\section{Benlik Saygısı ve İlişkisel Faktörler: Bir Meta-Analiz Çalışması*}

Türk Eğitim Bilimleri Dergisi

Makale Türü: Araştırma

Makale Geliş Tarihi: 10.05.20

Makale Kabul Tarihi: 25.09.20

Makale Yayın Tarihi: 28.12.20

ORCID: 0000-0001-5594-0786,

0000-0001-5753-9355

\author{
Tolga Seki ${ }^{1}$ Bülent Dilmaç
}

\title{
Öz
}

Araştırmada, benlik saygısı ile ilişkisi incelenen risk faktörleri ile koruyucu faktörlerin benlik saygısı üzerinde etki büyüklüğüne ilişkin genel bir sonuç elde etmek amaçlanmıştır. Bu doğrultuda, 2010-2019 yılları arasında yapılan çalışmalar incelenerek korelasyonel çalışmaların meta-analizi yapılmıştır. Yapılan araştırmada on dört faktörün benlik saygısı ile ilişkisinin etki büyüklüğü ayrı ayrı hesaplanmıştır. Elde edilen bulgulara göre yalnızlık ( $\mathrm{r}=-0.54)$ ile benlik saygısı arasında negatif yönlü güçlü düzeyde etki büyüklüğü elde edilmiştir. Çocukluk çağı travması $(r=-0.47)$, sosyal görünüş kaygısı ( $\mathrm{r}=-0.46)$, depresyon $(\mathrm{r}=-0.44)$, stres $(\mathrm{r}=-0.35)$ ile benlik saygısı arasında negatif yönlü orta düzeyde etki büyüklüğü elde edilmiştir. Anksiyete ( $\mathrm{r}=-0.27)$, güvenli olmayan bağlanma ( $\mathrm{r}=-0.18)$ ile benlik saygısı arasında negatif yönlü zayıf düzeyde etki büyüklüğü elde edilmiştir. Benlik saygısı ile koruyucu faktörler arasındaki ilişkilerin etki büyüklükleri incelendiğinde; psikolojik sağlamlık $(\mathrm{r}=0.47)$, öz yeterlik $(\mathrm{r}=0.41)$, yaşam doyumu $(\mathrm{r}=0.39)$, algılanan sosyal destek $(\mathrm{r}=0.32)$, problem çözme becerisi ( $\mathrm{r}=0.32)$, empati ( $\mathrm{r}=0.31$ ) ile benlik saygısı arasında pozitif yönlü orta düzeyde etki büyüklüğü elde edilmiştir. Güvenli bağlanma ( $\mathrm{r}=0.16)$ ile benlik saygısı arasında pozitif yönlü zayıf düzeyde etki büyüklüğü elde edilmiştir.

Anahtar Sözcükler: Benlik saygısı, Koruyucu faktörler, Risk faktörleri, Meta-analiz.

\begin{abstract}
In this research, the aim was to derive general conclusions about the effect of risk factors and protective factors on self-esteem by calculating effect sizes for the relationships between self-esteem, risk factors, and protective factors. Accordingly, a meta-analysis of correlational studies was conducted by examining the studies conducted between 2010-2019. In the research, the effect size of the relationship between fourteen factors and self-esteem was calculated separately. According to the findings, a large negative effect size was obtained between loneliness $(r=-0.54)$ and self-esteem. A moderate negative effect size was obtained between childhood trauma $(r=-0.47)$, social appearance anxiety $(r=-0.46)$, depression $(r=-0.44)$, stress $(r=-0.35)$, and self-esteem. A weak negative effect size was obtained between anxiety $(r=-0.27)$, unsafe attachment $(r=-0.18)$, and self-esteem. When the effect sizes of the relationships between self-esteem and protective factors are examined; a moderate positive effect size was obtained between self-respect and psychological resilience $(r=0.47)$, self-efficacy $(r=$ $0.41)$, life satisfaction $(r=0.39)$, perceived social support $(r=0.32)$, problem solving skill $(r=0.32)$, empathy $(r=0.31)$. A positive small effect size was obtained between secure attachment $(r=0.16)$ and self-esteem.
\end{abstract}

Keywords: Self-esteem, Protective factors, Risk factors, Meta-analysis.

\footnotetext{
* Bu makale Tolga Seki'nin doktora tezinden üretilmiştir.

${ }^{1}$ Tolga Seki, Arş. Gör. Dr., Necmettin Erbakan Üniversitesi, tlg.seki@gmail.com

2 Bülent Dilmaç, Prof. Dr., Necmettin Erbakan Üniversitesi, bulentdilmac@gmail.com
} 


\section{Giriş}

İnsanoğlunun temel yetilerinden biri olan düşünme, insanın doğadan başlayarak hem çevresi hem de kendisi üzerinde düşünmesine ve bir yargıya varmasına yol açmıştır. Kendisi üzerinde düşünen ve kendini anlamaya çalışan insanın bu yolculuğunda karşımıza çıkan ilk kavram benlik, öz kavramıdır. Tarihi süreç içerisinde bakıldığı zaman da benliğin ilk dönemlerde felsefenin konusu iken ilerleyen süreçte 1878 yılları itibari ile psikolojinin çalışma konularından biri olduğu söylenebilir (Rhodewalt ve Peterson, 2008). Literatürde benliği karşılayan çok sayıda kavram olup bunlar; öz, ego, kendilik, kişilik ve şahsiyettir (Burger, 2006; Cervone ve Pervin, 2016; Korkut Owen, 2015; Yörükoğlu, 1985, Türk Dil Kurumu [TDK], 2019). Benlik kişinin kişilik özelliklerini, değerlerini, inançlarını arzularını ve kendisi hakkındaki değerlendirmelerini kapsayan bir kavramdır. Benlik kişinin kendisine ve diğerlerine yönelik davranışlarını düzenleyen, kişiyi harekete geçiren ve bunlar arasındaki süreçlere aracılık eden dinamik ve zihinsel bir sistemdir (Gerring ve Zimbardo, 2012). Benlik kavramı, çevre ile kurulan ilişkiler ve yeni öğrenmeler neticesinde oluşmaktadır. İnsanlar davranış sergilerken de bu benlik kavramlarına uygun ve tutarlı bir şekilde davranma eğiliminde olmaktadır (Kulaksizoğlu, 2011).

Benlik kavramı kişinin kendine yönelik yapmış olduğu nitelendirmeler anlamına gelirken benlik saygısı kişinin bu nitelendirmeler üzerine yaptı̆̆ı değerlendirmeler olarak ifade edilebilir. Yani benlik kişinin kendini nötr bir şekilde tanımlaması ve algılaması iken benlik saygısı bu algıya duyguların da dahil olmasıdır (Videbeck, 2001; Woolfolk, 2004). Dış dünyadaki nesnelere ilişkin bir tutuma sahip olan insanın, kendi benliğine yönelik de bir tutumu bulunmaktadır. Benlik saygısı, kişinin benliğine ilişkin duygu, düşünce ve inançlarını kapsayan bir yapıdır (Rosenberg, 1986). Özcan ve arkadaşlarına (2013) göre ise benlik saygısı, kişinin kendini üstün ya da aşağı görmeksizin kendini değerlendirmesi neticesinde kendi benliğini onaylamasından kaynaklanan beğeni durumu, kendini sevilmeye ve beğenilmeye değer görme, kendinden memnun olma ve özüne güvenme durumudur. Bir başka ifade ile kişinin kendine ne kadar değer verdiğini, kendini değerli bulup bulmadığına ilişkin algısını ifade etmektedir (Rosenberg, 1965).

Doğumla birlikte yaşamın ilk yıllarında oluşmaya başlayan ve yaşam boyu gelişmeye ve değişmeye devam eden benlik saygısı, çevre ile etkileşim yoluyla şekillenmektedir. Bebeklik döneminde anne-babayla ya da bakıcılarla etkileşim önemli iken ilerleyen yıllarda da içinde bulunulan sosyal ortam, alınan geri dönütler benlik saygısının gelişiminde önem arz etmektedir (Chao, Vidacovich ve Green, 2017). Bunun yanı sıra benlik saygısı yaşanan olaylara ya da durumlara göre birden değişim gösteren bir yapı değildir. Bu açıdan benlik saygısının uzun süre değişmeyen genel bir kişilik özelliği olduğunu söylemek mümkündür (Işın, 2015). Ancak, bireyin benlik saygısının düşük ve yüksek olmasında doğrudan veya dolaylı olarak etkili olan birtakım faktörler bulunmaktadır. Bu 
faktörler ise kişiden kişiye değişiklik gösterebilmektedir (Burger, 2006). Ancak bunları açıklamadan önce yüksek ve düşük benlik saygısının ne anlama geldiğini açıklamak yararlı olacaktır.

Benlik saygısının yüksek olması, kişinin kendini gerçekçi ve sağlıklı bir şekilde değerlendirmesi neticesinde oluşan ve aynı zamanda kendine değer vermesi ile sonuçlanan duygu ve düşüncelerin toplamıdır. Benlik saygısı yüksek olan kişiler kendilerini sevilmeye ve saygı duyulmaya değer görmektedir (Byrne ve O'brien, 2014). Benlik saygısının yüksek olması, bireyin kendine ve diğer insanlara karşı iyimser olması, risk almak ve rekabete girmek konusunda cesur olması, karşılaştı̆̆ zorluklarla mücadele etmesi ve hayatı anlamlı bulması ile bağdaştırılabilir (Yörükoğlu, 1990). Düşük benlik saygısı ise kişinin kendini devamlı ve kalıcı olarak olumsuz değerlendirmesidir. Kişinin kendini değersiz görmesi ve kendi hakkında olumsuz düşünce ve duygularını dile getirmesidir (Fennel, 1997). Benlik saygısı düşük olan kişiler sahip oldukları becerileri önemsemez, kolay kolay kendine güven duymaz, kendine saygısı düşüktür, çoğu zaman başarılarını kabul etmez ve benliğini korumak için diğer insanlarla ilişkiye girmekten kaçınır. Bu sebeple kendilerine ilişkin algılamaları kararsız, tutarsız, karmaşık ve belirsiz bir niteliğe sahiptir (Byrne ve O'brien, 2014).

Literatürde benlik saygısını etkileyen etmenlere bakıldığında çok sayıda faktörün olduğunu söylemek mümkündür. Çoban (2019), benlik saygısına etki eden başlıca faktörleri aile, sosyal çevre, cinsiyet şeklinde sıralamıştır. Bunların yanı sıra benlik saygısının gelişiminde etkili olan kişilik özellikleri, benlik imajı, depresyon, aile ilişkileri, yaratıcılık, anne-baba tutumu, duygusal ve bilişsel tepkiler, benlik algısı, ruhsal ve medeni durum ve psikolojik danışmadır. Bu faktörlerin bir kısmı yüksek benlik saygısı ile ilişkili iken bir kısmı da düşük benlik saygısı ile ilişkilidir. Araştırma kapsamında ele alınan ve yüksek benlik saygısı ile ilişkili faktörler koruyucu faktörler, düşük benlik saygısı ile ilişkili olan faktörler risk faktörleri adı altında toplanmıştır. Risk faktörleri, problemlerin meydana gelmesi veya artmasına yol açabilecek genellikle psiko-sosyal temelli faktörleri kapsamaktadır (Korkut Owen, 2015). Koruyucu faktörler ise risk faktörlerinin tam tersine yaşanan olumsuz deneyimler karşısında kişinin yapıcı tepkiler vermesini kolaylaştıran faktörler olarak ifade edilebilir (Karaırmak, 2006). İki tür koruyucu etmen bulunmaktadır, bireysel özellikler ve sosyal çevre ile ilgili etmenler (sosyal destek, anne baba yetiştirme tarzı vb.).

Araştırma kapsamında ele alınan risk etmenleri; depresyon, anksiyete, stres, yalnızlık, güvenli olmayan bağlanma türleri, çocukluk çağı travması, sosyal görünüş kaygısı iken koruyucu etmenler algılanan sosyal destek, yaşam doyumu, psikolojik sağlamlık, problem çözme becerisi, güvenli bağlanma, öz-yeterlik ve empatidir.

Anksiyete her insan tarafından zaman zaman yaşanan korkuya benzer bir duygudur ve gerçekçi, nevrotik ve vicdani olarak adlandırılan türlere sahiptir. Belirtileri açısından çoğu zaman anksiyeteye benzeyen bir başka duygu-durum bozukluğu da depresyondur (Arslan, Mergen, 
Erdoğmuş Mergen, Arslan ve Ayyıldız, 2016). Depresyon; endişe, büyük üzüntü, değersizlik ve suçluluk duyguları ile birlikte başkalarından uzaklaşma, iştah, uyku, cinsel isteksizlik ve günlük etkinliklere karşı ilgi kaybı ile karakterize olan bir duygu durum bozukluğudur (Kılınç ve Torun, 2011). Anksiyete bozuklukları ve depresyon benlik saygısı ve sosyal görünüş kaygısına yol açabilen klinik durumlardır. Sosyal görünüş kaygısı, kişinin görünüşüne ve bedenine ilişkin imajını olumsuz olarak değerlendirmesidir. Sosyal kaygısı olan kişilerin çoğu depresyonda olduğu gibi kendi değerine ve önemine dair negatif inançlara sahiptir. Olumlu beden algısı benlik saygısının yüksek oluşu ile ilişkili iken olumsuz beden algısı benlik saygısının düşük oluşu ile ilişkilidir (Özcan ve arkadaşları, 2013). Düşük benlik saygısı ile ilişkili olan bir diğer faktör ise yalnızlıktır. Yalnızlık diğer insanlara ihtiyaç hissetmek ve bununla birlikte insanlardan çok uzak olduğunu fark ederek olumsuz duygular yaşamaktır (Copel, 1988).

Bowlby'e (1973) göre bağlanma, bireylerin önem verdiği diğer insanlarla olan güçlü duygusal bağ kurma eğilimini ifade etmektedir. Yersel'in (2019), yaptığı araştırmada güvenli bağlanma stiline sahip kişilerin benlik saygısının güvensiz bağlanan kişilerden daha yüksek olduğu ortaya konmuştur. Benlik saygısı üzerinde olumsuz bir etkisi olan çocukluk çağı travmaları ise erken dönemde yaşanan birtakım ihmal ve istismar yaşantılarını ifade etmektedir (Kulaksızoğlu, 2011).

Öz-yeterlik kavramı ilk defa Bandura tarafından ortaya atılmış olup kişinin performansını gerçekleştirmek üzere kendine olan inancıdır. Bandura (1997) tarafından bir konu hakkındaki özyeterlik algılarının benlik saygısı üzerinde etkili olabileceği ifade edilmiştir. Bu iki kavram birbirine benzemekle birlikte, benlik saygısı daha geniş kapsamlıdır. Yaşam doyumu kişinin yaşam koşullarına dair kriterlerini bilişsel ve bilinçli bir şekilde değerlendirmesidir (Pavot ve Diener, 1993). Bu değerlendirme süreci kişinin belirli olay ya da durumlara bağlı olarak yaşadığı anlık duygulardan ziyade uzun dönemli duygu durumunu ifade etmektedir (Diener, 1984). Yüksek benlik saygısı ile ilişkili (Traş, Arslan ve Mentiş Taş, 2011) olan bir diğer etken de problem çözme becerisidir. Problem çözme, bir problemi çözmek için geçmiş deneyimler yolu ile öğrenilen yolların ötesine geçerek yeni çözüm yolları bulabilme becerisi olarak ifade edilebilir (Traş, Arslan ve Mentiş Taş, 2011). Psikolojik sağlamlık, en genel anlamda stres ve zorlu durumlara uyum gösterme yeteneği olarak tanımlanmaktadır (Rutter, 2007). Gizir (2007) benlik saygısını, psikolojik sağlamlık açısından koruyucu bir faktör olarak ele almıştır. Algılanan sosyal destek, kişinin yardıma ihtiyaç duyduğu zaman, çevresinden bu yardımın geleceğine dair inancını ifade etmektedir (Goldsmith, 2008). Çakar ve Karataş'ın (2012), araştırmalarında benlik saygısı yüksek ergenlerin daha fazla sosyal destek algıladığı ortaya konmuştur. İnsanların olumlu ve yüksek benlik saygısına sahip olmasında etkili olan faktörlerden biri de empatidir (Rosenberg ve Turner,1990). Empati diğerinin duygularının yoğunluğunu ve anlatımını algılama ve anlama becerisidir (Whirter ve Voltan-Acar, 1985). 
Literatür incelendiğinde yüksek benlik saygısı ve düşük benlik saygısı ile ilişkili birçok faktör olduğu görülmektedir. Bu faktörlerin ilişki düzeyini inceleyen çalışmalar farklılık gösterebilmektedir. $\mathrm{Bu}$ açıklamalar doğrultusunda araştırmanın problem cümlesi “Benlik saygısı ile risk etmenleri (depresyon, anksiyete, stres, yalnızlık, güvenli olmayan bağlanma türleri, çocukluk çağı travması, sosyal görünüş kaygısı) ve koruyucu etmenler (algılanan sosyal destek, yaşam doyumu, psikolojik sağlamlık, problem çözme becerisi, güvenli bağlanma, öz-yeterlik ve empati) arasındaki ilişkinin etki büyüklüğü yönü ve düzeyi nedir?" dir.

\section{Yöntem}

Yapılan araştırmada benlik saygısı ile ilişkisi incelenen risk faktörleri (depresyon, anksiyete, stres, yalnızlık, güvenli olmayan bağlanma, çocukluk çağı travması ve sosyal görünüş kaygısı) ile koruyucu faktörlerin (algılanan sosyal destek, yaşam doyumu, psikolojik sağlamlık, problem çözme becerisi, güvenli bağlanma, öz-yeterlik ve empati) benlik saygısı üzerinde etki büyüklügüne ilişkin genel bir sonuç elde etmek amaçlanmıştır. Bu amaç ile benlik saygısı ile araştırmada belirlenen ilişkisel faktörler arasındaki korelasyonel çalışmalarının meta-analizi yapılmıştır. Tarihsel zaman içinde benlik saygısı ile ilişkili faktörlerin gücünün değişebilecek olması ve benlik saygısı konulu araştırmaların çok büyük bir bölümü içermesi nedeni ile son on yıla ait çalışmalar araştırmaya dâhil edilmiştir.

Meta-analiz farklı çalışmalardan elde edilen sonuçların birleştirilerek genel bir sonuç elde edilmesi için yapılan analiz olarak tanımlanmaktadır (Dinçer, 2014). Yapılan araştırma bu doğrultuda desenlenmiştir. Meta-analiz bir konu hakkındaki benzer çalışmalar belli ölçütler altında gruplandırılıp bu çalışmalara ait nicel bulgular birleştirilerek yorumlanma sürecini içermektedir (Dinçer, 2014). Bu yöntem, bir konu hakkında çeşitli çalışmaların sonuçlarını özetleyen nicel veriler sunmakta ve araştırmacıya konu hakkında genel bir yargıya ulaşma imkânı sağlamaktadır (Robinson, Lloyd ve Rowe, 2008).

\section{Verilerin Toplanması}

Türkiye'de benlik saygısı ve araştırmada incelenen ilişkisel faktörleri konu edinen hakemli bilimsel dergilerde yayınlanmış makaleler ve Türkiye'de yazılan lisansüstü tezler araştırmanın temel veri kaynağını oluşturmaktadır. İlgili araştırmalara ulaşmak için anahtar kelimeler Türkçe ve İngilizce olarak taranmıştır.

Verilerin toplanmasında; YÖK Ulusal Tez Merkezi, YÖK Akademik, DergiPark Akademik, Google Scholar, EBSCO Host, Web of Science, Necmettin Erbakan Üniversitesi Kütüphanesi ve abone olunan veri tabanları, ULAKBİM Sosyal ve Beşeri Bilimler Veri Tabanı kullanılmıştır. Araştırmaya dâhil edilen çalışmaların seçiminde kullanılan ölçütler şunlardır:

1. Çalışmaların 2010-2019 yılları arasında yapılmış olması. 
2. Çalışmaların etki büyüklüğünün hesaplanabilmesini sağlayacak sayısal verileri içermesi.

3. Lisansüstü tezlere tam metin olarak ulaşılabilmesi.

4. Makalelerin hakemli bilimsel dergilerde yayınlanmış olması.

5. Çalışmaların dilinin Türkçe ya da İngilizce olması.

6. Çalışmaların Türkiye örnekleminde gerçekleştirilmiş olması.

Meta-analizde 1151 çalışma incelenmiştir. Araştırma kapsamında incelenen çalışmalardan araştırma kriterlerini karşılayan 153 farklı çalışma elde edilmiş ve bu çalışmalardan 237 etki büyüklüğü hesaplanmıştır. Çalışmaların 106'sı (\%69) tez, 47'si (\%31) makaleden oluşmaktadır.

\section{Kodlama Sürecinin Geçerlik ve Güvenilirliği}

Benlik saygısı ve araştırma kapsamında incelenen ilişkisel faktörler ile yapılmış çalışmalar meta-analize dâhil edilmeden önce kategorik değişkenlere dönüştürecek kodlama yöntemi geliştirilerek açık ve detaylı bir şekilde kodlanmıştır. Öncelikle her bir çalışma numaralandırılmıştır. Daha sonra çalışmaların her biri araştırmacı tarafından hazırlanan kodlama formu kullanılarak kaydedilmiştir. Kodlama formunda yer alan bilgiler şunlardır: Çalışmanın adı, yazarı, yayın yılı, yayın türü (makale, tez), çalışmanın gerçekleştirildiği örneklem, uygulanan ölçek bilgileri ve özellikleri, örneklem sayısı, korelasyon değerleri, ilişkinin yönüdür.

Araştırmada kodlanan verilerin güvenirliğini sağlamak amacıyla eğitim bilimleri alanında doktora aşamasında ikinci bağımsız kodlayıcı tarafından kodlanması sağlanmış ve kodlayıcı arasındaki uyum değerlendirilmiştir. Kodlayıcılar arası uyumun belirlenmesi için Cohen Kappa katsayısı hesaplanmış ve $\kappa=0.90$ (0.80-1.00 arası mükemmel uyum) olarak bulunmuştur.

Bir meta-analiz çalışmasının geçerliği araştırmaya dâhil edilen çalışmaların geçerliği oranında geçerlidir (Petitti, 2000). Bu nedenle meta-analize dâhil edilen tüm çalışmaların geçerlik bulguları incelenmiş ve çalışmaların geçerliğinin sağlandığı görülmüştür (Robinson, Lloyd ve Rowe, 2008). Bu bağlamda çalışmada belirlenen ilişkisel faktörlere ait araştırmaların tümüne ulaşılmıştır.

\section{Verilerin Analizi}

Verilerin analizi süreci her bir çalışma için etki büyüklüğünün hesaplanması, yayın yanlılığının kontrolü, heterojenlik testi ve birleştirilmiş etki büyüklüğünün hesaplanması sürecini içermektedir. Analizler için Comprehensive Meta-Analysis yazılımı kullanılarak yapılmıştır. Yapılan araştırmada sosyal bilimler alanına uygun olarak rastgele etkiler modeli kullanılmıştır (Cumming, 2012). Cohen, Manion ve Morrison'a (2007) göre korelasyonel çalışmalarda etki büyüklüğü değerleri şu şekilde yorumlanmıştır: $\mathrm{r}<0.10$ ise çok zayıf, $0.10 \leq \mathrm{r}<0.30$ ise zayıf, $0.30 \leq \mathrm{r}<0.50$ ise orta, $0.50 \leq \mathrm{r}<$ 0.80 ise güçlü, $r \geq 0.80$ ise çok güçlü düzeyde etki. Araştırmada yayın yanlılığını tespit etmek için 
Orwin's Fail-Safe N, Begg ve Mazummar sıra korelasyonları, Egger'in Regresyon Testi analizleri yapılmıştır. Araştırmada heterojenliğin kontrolü Cochran'ın (1954) Q istatistiği ve $I^{2}$ istatistiği ile gerçekleştirilmiştir.

\section{Bulgular}

Bu bölümde araştırmaya dâhil edilen çalışmaların yayın yanlılığı, Heterojenlik Testi sonuçları, ve çalışmalara ait birleştirilmiş etki büyüklükleri verilmiştir. Araştırmaya dâhil edilen çalışmaların yayın yanlılığı ve Heterojenlik Testi sonuçları, Tablo 1'de verilmiştir.

Tablo 1. Yayın Yanlılığı ve Heterojenlik Sonuçları

\begin{tabular}{|c|c|c|c|c|c|c|}
\hline İlişkisel Faktörler & $\mathbf{k}$ & $\begin{array}{l}\text { Fail-Safe } \\
\quad \pm 0.01\end{array}$ & $\begin{array}{l}\text { Begg ve } \\
\text { Mazum }\end{array}$ & Egger & $Q(d f)$ & $\mathbf{I}^{2}$ \\
\hline \multicolumn{7}{|l|}{ Risk Faktörleri } \\
\hline Depresyon & 54 & 2556 & 0.39 & 0.26 & $695.83(53)$ & 92.38 \\
\hline Anksiyete & 25 & 589 & 0.15 & 0.26 & $339.07(24)$ & 92.92 \\
\hline Stres & 6 & 205 & 0.42 & 0.38 & $30.48(6)$ & 93.59 \\
\hline Yalnızlık & 17 & 1073 & 0.40 & 0.18 & $395.27(16)$ & 95.95 \\
\hline Güvenli olmayan & 25 & 498 & 0.14 & 0.00 & $99.89(24)$ & 75.97 \\
\hline Çocukluk çağı & 7 & 384 & 0.44 & 0.39 & $222.59(6)$ & 97.30 \\
\hline Sosyal görünüş kaygısı & 10 & 502 & 0.39 & 0.26 & $18.78(9)$ & 52.05 \\
\hline \multicolumn{7}{|l|}{ Koruyucu Faktörler } \\
\hline Algilanan sosyal & 22 & 724 & 0.32 & 0.29 & $120.58(21)$ & 82.58 \\
\hline Yaşam doyumu & 23 & 966 & 0.33 & 0.19 & $219.67(22)$ & 89.98 \\
\hline Psikolojik sağlamlık & 15 & 766 & 0.21 & 0.39 & $277.36(14)$ & 96.65 \\
\hline Problem çözme & 10 & 313 & 0.29 & 0.21 & $25.01(9)$ & 64.01 \\
\hline Güvenli bağlanma & 9 & 137 & 0.20 & 0.21 & $9.03(8)$ & 11.44 \\
\hline Öz yeterlik & 7 & 283 & 0.22 & 0.33 & $67.37(6)$ & 91.09 \\
\hline Empati & 7 & 314 & 0.32 & 0.08 & $161.89(6)$ & 96.29 \\
\hline
\end{tabular}

Yayın yanlılığını tespit etmek için Orwin's Fail-Safe N, Begg ve Mazummar sıra korelasyonları, Egger' in Regresyon Testi analizleri yapılmıştır. Orwin's Fail Safe N analizi sonucuna göre meta-analiz sonucu elde edilen etki büyüklüğü değerini, önemsiz etki büyüklüğü değeri olan \pm 0.01 düzeyine düşürebilmek için araştırmaya etki büyüklüğü 0.00 olan kaç adet çalışmaya ihtiyaç duyulduğunu gösterir. Elde edilen değerin araştırmaya dâhil edilen çalışma sayısının oldukça üzerinde olması, yayın yanlılı̆̆ı olmadığını göstermektedir. Begg ve Mazumdar sıra korelasyonları ve Egger'in Regresyon Testi analizine göre $p$ değeri istatistiksel olarak anlamlı bulunmamıştır ( $p>05$ ). İstatistiksel olarak anlamlı düzeyde bulunmayan Begg ve Mazumdar ve Egger değeri yayın yanlılığı olmadığının göstergesidir (Özgözgü ve Altunay, 2016; Sedgwick, 2013). Elde edilen bulgular incelendiğinde araştırmaya dâhil edilen tüm ilişkisel faktörlerin yayın yanlılığı göstermediği bulunmuştur. 
Meta analiz kapsamına alınan çalışmaların Heterojenlik Testi'nde $Q$ değerinin kay-kare tablosundaki serbestlik derecesine (df) karşılık gelen değeri aşması çalışmaların heterojen dağılım gösterdiği anlamına gelmektedir (Higgins ve Thompson, 2002). $\mathrm{I}^{2}$ değeri mevcut araştırmaların varyansı açıklama yüzdesi ile ilgilidir ve \%50'nin üzerinde olması çalışmaların heterojen dağılım gösterdiği şeklinde yorumlanmaktadır (Petiti, 2000). Çalışmalara ait $Q$ değeri ve $I^{2}$ sonuçları incelendiğinde güvenli bağlanma haricinde tüm çalışmaların heterojen dağıldığı görülmüştür. Araştırmaya dâhil edilen çalışmalara ait birleştirilmiş etki büyüklükleri Tablo 2'de verilmiştir.

Tablo 2. Benlik Saygısı ile İlişkisel Faktörler Arasındaki İlişkiye Dayalı Etki Büyüklüğü

\begin{tabular}{|c|c|c|c|c|}
\hline İlişkisel Faktörler & $K$ & $N$ & $E S$ & 95\%C.I \\
\hline \multicolumn{5}{|l|}{ Risk Faktörleri } \\
\hline Depresyon & 54 & 11761 & $-0.44^{*}$ & {$[-0.49,-0.38]$} \\
\hline Anksiyete & 25 & 3107 & $-0.27^{*}$ & {$[-0.39,-0.14]$} \\
\hline Stres & 6 & 1378 & $-0.35^{*}$ & {$[-0.46,-0.22]$} \\
\hline Yalnızlık & 17 & 7374 & $-0.54^{*}$ & {$[-0.62,-0.45]$} \\
\hline Güvenli olmayan bağlanma & 25 & 2154 & $-0.18^{*}$ & {$[-0.23,-0.12]$} \\
\hline Çocukluk çağı travması & 7 & 1511 & $-0.47^{*}$ & {$[-0.68,-0.18]$} \\
\hline Sosyal görünüş kaygisı & 10 & 5683 & $-0.46^{*}$ & {$[-0.50,-0.43]$} \\
\hline \multicolumn{5}{|l|}{ Koruyucu Faktörler } \\
\hline Algilanan sosyal destek & 22 & 4942 & $0.32^{*}$ & {$[0.25,0.38]$} \\
\hline Yaşam doyumu & 23 & 7615 & $0.39^{*}$ & {$[0.33,0.45]$} \\
\hline Psikolojik sağlamlık & 15 & 4949 & $0.47^{*}$ & {$[0.37,0.57]$} \\
\hline Problem çözme becerisi & 10 & 3547 & $0.32^{*}$ & {$[0.27,0.38]$} \\
\hline Güvenli bağlanma & 9 & 1507 & $0.16^{*}$ & {$[0.11,0.22]$} \\
\hline Öz yeterlik & 7 & 2752 & $0.41^{*}$ & {$[0.92,0,51]$} \\
\hline Empati & 7 & 1422 & $0.31^{*}$ & {$[0.03,0,54]$} \\
\hline
\end{tabular}

$\overline{k=\text { çalışma sayısı, } N=\text { toplam örneklem sayısı } E S=\text { etki büyüklüğü (pearson } r \text { ) 95\%C.I= güven aralığı }}$, ${ }^{*} p<0.05$

Yapılan araştırmada on dört faktörün benlik saygısı ile ilişkisinin etki büyüklügü hesaplanmıştır. Elde edilen bulgulara göre yalnızlık $(\mathrm{r}=-0.54, p<0.05)$ ile benlik saygısı arasında negatif yönlü güçlü düzeyde etki büyüklüğü elde edilmiştir. Çocukluk çağı travması ( $r=-0.47, p<0.05)$, sosyal görünüş kaygisı $(\mathrm{r}=-0.46, p<0.05)$, depresyon $(\mathrm{r}=-0.44, p<0.05)$, stres $(\mathrm{r}=-0.35, p<0.05)$ ile benlik saygısı arasında negatif yönlü orta düzeyde etki büyüklüğü elde edilmiştir. Anksiyete $(r=-0.27, p<0.05)$, güvenli olmayan bağlanma $(r=-0.18, p<0.05)$ ile benlik saygısı arasında negatif yönlü zayıf düzeyde etki büyüklüğü elde edilmiştir.

Benlik saygısı ile koruyucu faktörler arasındaki ilişkilerin etki büyüklükleri incelendiğinde psikolojik sağlamlık $(\mathrm{r}=0.47, p<0.05)$, öz yeterlik $(\mathrm{r}=0.41, p<0.05)$, yaşam doyumu $(\mathrm{r}=0.39, p<0.05)$, algilanan sosyal destek $(\mathrm{r}=0.32, p<0.05)$, problem çözme becerisi $(\mathrm{r}=0.32, p<0.05)$, empati $(\mathrm{r}=0.31, p<0.05)$ 
ile benlik saygısı arasında pozitif yönlü orta düzeyde etki büyüklüğü elde edilmiştir. Güvenli bağlanma $(r=0.16, p<0.05)$ ile benlik saygısı arasında pozitif yönlü zayıf düzeyde etki büyüklüğü elde edilmiştir.

\section{Tartışma}

Benlik saygısı konulu çalışmaların 1980'li yıllara kadar uzandığı ancak yapılan çalışmaların geçmişten günümüze her yıl artarak devam ettiği, son on yılda gerçekleştirilen çalışmaların toplam çalışmaların çok büyük bir kısmını oluşturduğu görülmüştür. Bu çalışmada, hem güncel verileri içermesi hem de örneklemin büyük bir kısmını kapsaması nedeniyle son on yıldaki çalışmalar incelenmiştir. Araştırmaya sadece Türkiye'de gerçekleştirilen çalışmalar dâhil edilmiştir. Ayrıca araştırmaya bir jüri tarafından değerlendirilmiş olması ya da bir hakem sürecinden geçmiş olması nedeni ile makale ve tez türünden çalışmalar dâhil edilmiştir.

Yapılan meta-analiz sonucunda elde edilen bulguların güven aralıklarının dar olması çalışma sonuçlarının güvenilir olduğunu göstermektedir. Meta-analize ait $Q$ değerleri kay kare değerlerinden yüksek bulunmuştur. Bu değerler çalışmaların heterojen dağılım gösterdiği anlamına gelmektedir. Elde edilen etki büyüklükleri araştırmada incelenen ilişkilerin yönü ve gücü hakkında güvenilir bulgular sunmaktadır. Bu bakımdan önemli bulgu olarak değerlendirilebilir. Benlik saygısı ile ilişkili risk faktörlerinin etki büyüklükleri sırasıyla yalnızlık (-0.54), çocukluk çağı travması (-0.47), sosyal görünüş kaygısı (-0.46), depresyon (-0.44), stres (-0.35), anksiyete (-0.27), güvenli olmayan bağlanma (0.18) şeklindedir. Benlik saygısı ile koruyucu faktörlerin etki büyüklükleri sırasıyla psikolojik sağlamlık (0.47), öz yeterlik (0.41), yaşam doyumu (0.39), algılanan sosyal destek (0.32), problem çözme becerisi (0.32), empati (0.31), güvenli bağlanma (0.16) şeklindedir.

Yalnızlık ve benlik saygısı arasında negatif ilişki görülmesi beklenen bir durum olmakla birlikte aralarındaki ilişkiye ait etki büyüklüğünün oldukça yüksek olması oldukça manidardır. Yalnızlık güçlü bir duygudur ve sosyo-demografik değişiklikler bu durumu daha da kötüleştirmektedir (Ernst ve Cacioppo, 1999). Ülkemizde de modernleşme ile birlikte kültürel bir dönüşüm yaşanmakta ve bireysellik daha çok desteklenir hâle gelmektedir. Çağdaşlaşmanın toplumsal yapı üzerindeki etkileri duygusal, fiziksel ve psikolojik sorunların temelini oluşturan yalnızlığa neden olmaktadır (Ernst ve Cacioppo, 1999). Yalnızlık sadece düşük benlik saygısı ile değil, depresyon, anksiyete, saldırganlık gibi ruhsal problemlerle ilişkili bir kavramdır (Jackson ve Cochran, 1991).

Yalnızlığın zıddı olarak aile ve akran bağlılığının artması da benlik saygısı ile pozitif ilişkili olacaktır. Bu bağlamda Gorrese ve Ruggieri (2013), çalışmalarında benlik saygısı ve akran bağlılığı arasındaki ilişkiyi incelemiş ve yapılan meta-analiz sonucunda 0.27 etki büyüklüğü elde edilmiştir. Elde edilen etki büyüklügü çok yüksek olmasa da araştırma bulgularını destekler niteliktedir. 
Yapılan araştırmada çocukluk çağı travması ile benlik saygısı arasında -0.47 düzeyinde etki büyüklüğü elde edilmiştir. Çocukluk çağı travmaları güvensiz bağlanma, düşük benlik saygısı, okul başarısızlığı, davranış problemleri, suça yönelme, depresyon gibi problemler ile ilişkili bir kavramdır (Yılmaz Irmak, 2016). Jumper (1995), çalı̧̧masında çocukluk dönemi cinsel istismar ile yetişkinlik dönemi ruhsal uyumu arasındaki ilişkiyi meta analiz yöntemi ile incelemiş ve cinsel istismar yaşantısı ile düşük benlik saygısı arasında r=0.17 etki büyüklüğü elde edilmiştir. Bu sonuç araştırmadan elde edilen -0.47 etki büyüklüğünden daha düşük olmakla birlikte araştırmayı destekler niteliktedir.

İnsanlar başkaları üzerinde istendik etkiler bırakmak ister ancak bu konuda kendilerinden şüphe etmeleri sosyal görünüş kaygısına neden olabilmektedir (Hart ve arkadaşları, 2008). Bu sadece fiziksel görünüş ile ilgili olmayıp beden algısı ile daha çok ilişkilidir. Miller ve Downey (1999), gerçekleştirdikleri çalışmada ağırlık ve benlik saygısı arasındaki ilişkiyi meta-analiz yöntemi ile incelemiştir. Araştırma sonuçlarına göre gerçek ağırlık ile benlik saygısı arasında -0.12, algılanan kilo ile benlik saygısı arasında -0.34 etki büyüklüğü elde etmiştir. Bu sonuç bireylerin kendine yönelik değerlendirmelerinin ne kadar etkili olduğunu ortaya koymakta olup yapılan araştırmada da benlik saygısı ile sosyal görünüş kaygısı arasında elde edilen -0.46 etki büyüklüğünü anlamlı kılmaktadır.

Yapılan araştırmada benlik saygısı ile depresyon (-0.44), stres (-0.35), anksiyete (-0.27) arasında negatif etki büyüklüğü elde edilmiştir. Benlik saygısı ile depresyon arasındaki ilişkinin niteliği birçok çalışmaya konu olmuştur. Orth ve Robins (2013), düşük benlik saygısı ve depresyon arasındaki ilişkinin niteliğini araştırmış ve aralarındaki ilişkinin niteliği hakkında çeşitli modeller geliştirmişlerdir. Konu hakkında yapılmış çalışmaları inceleyen araştırmacılar düşük benlik saygısının depresyona katkı sağladığı yönünde kanıtlar elde ederken depresyonun benlik saygısına katkı sağladığı yönünde zayıf kanıtlar da elde etmişlerdir. Ayrıca çalışma kapsamında düşük benlik saygısının stres yaşantıları üzerinden depresyona etki edebileceğine dair kanıtlar bulmuşlardır.

Karadağ ve Sölpük (2018), depresyon ve kaygı belirtileri arasındaki ilişkiyi meta-analiz yöntemi ile incelemiş araştırma sonucunda depresyonun kaygı üzerinde geniş düzeyde pozitif etkiye sahip olduğu saptanmıştır. Elde edilen bulgular doğrultusunda depresyon ve kaygının diğer değişkenlerle olan ilişkisinde benzer sonuçlar göstermesi beklenen bir durumdur. Sowislo ve Orth (2013), çalışmalarında benlik saygısı, depresyon ve kaygı arasındaki ilişkiyi meta-analiz yöntemi ile incelemiştir. Elde edilen bulgulara göre depresyon ile benlik saygısı arasında $r=-0.57$ anksiyete ile benlik saygısı arasında $=-0.40$ düzeyinde etki büyüklüğü elde edilmiştir. Yapılan araştırmada da benzer şekilde depresyon ile benlik saygısı arasında daha güçlü bir ilişki elde dilmiştir.

Yapılan araştırmada güvenli olmayan bağlanma stilleri ile benlik saygısı arasında -0.18 etki büyüklüğü elde edilmiştir. Ayrıca araştırmada güvenli bağlanma stili ile benlik saygısı arasında 0.16 etki büyüklüğü elde edilmiştir. Hao ve Wilkonson (2014), meta- analiz çalışmasında bağlanma stilleri 
ile benlik saygısı arasındaki ilişkiyi incelemiştir. Yapılan araştırmada bağlanma stillerinin kaygı faktörü ile benlik saygısı arasında -0.38 , kaçınma faktörü ile benlik saygısı arasında -0.23 etki büyüklüğü elde edilmiştir.

Mattanah, Lopez ve Govern (2011), bağlanma ve benlik saygısı arasındaki ilişkiyi meta-analiz yöntemi ile incelemiştir. Araştırmada kaygıllı, kaçınmacı, korkulu ve saplantılı bağlanma stilleri ile benlik saygısı arasında zıt yönlü, güvenli ve kayıtsız bağlanma biçimleri ile benlik saygısı arasında da aynı yönlü ilişki elde edilmiştir (Akt. Kan, 2018). Araştırmada güvenli bağlanma ile benlik saygısı arasında pozitif, güvenli olmayan bağlanma ile benlik saygısı arasında negatif ilişki elde edilmiş olup elde edilen bu sonucun literatür ile uyumlu olduğu görülmüştür.

Yapılan araştırmalar benlik saygısı yüksek olan bireylerin diğer bireyler tarafından daha fazla sosyal destek aldığı ve takdir edildiğini göstermektedir (Kayal, 2018; Soylu, 2016; Taşören, 2013). Yalçın (2014), sosyal destek ile çeşitli değişkenler arasındaki ilişkiyi meta-analiz aracılığı ile incelemiştir. Araştırmasında sosyal destek ile iyi oluş arasında pozitif, depresyon ve yalnızlık ile negatif yönde ilişki bulmuştur. Yalçın (2014), ayrıca araştırmasında sosyal destek ile öz saygı arasında 0.24 etki büyüklüğü elde etmiştir. Araştırma bulguları algılanan sosyal destek ile benlik saygısı arasında pozitif ilişki olduğunu göstermektedir ve çalışmada elde edilen .32 etki büyüklüğünü doğrular niteliktedir.

Yapılan araştırmada psikolojik sağlamlık ile benlik saygısı arasında 0.47 etki büyüklüğü ile güçlü pozitif korelasyon elde edilmiştir. Araştırmaya dâhil edilen çalışmaların tamamında pozitif ilişki görülmüştür. Çalışmaların çok büyük bölümünün son üç yılda gerçekleştirilmiş olması bu ilişkinin önemine ve güncelliğine dikkat çekmektedir. Psikolojik sağlamlık bir kişilik özelliğidir ve stres durumlarının etkisini azaltmaktadır. Psikolojik dayanıklılığı yüksek kişiler yaşamlarını kontrol altında tutar ve beklenmedik durumları gelişme için bir fırsat olarak görürler. Bu kişiler problem çözme becerisi gelişmiş, kişiler arası etkili iletişim kurabilen, kendini geliştiren, olumlu benlik tasarımına sahip ve öz saygısı yüksek kişilerdir (Gürgan, 2006).

Araştırmada yüksek benlik saygısı ile ilişkili kavramlardan biri de yaşam doyumudur. Araştırmada 23 çalışmadan elde edilen etki büyüklüğü $0.39^{\prime}$ dur. Benlik saygısı, bireyin kendini değerlendirmesini yansıtırken yaşam memnuniyeti bireyin bir bütün olarak kişinin yaşamını değerlendirmesini içerir (Civitci ve Civitci, 2009). Her iki değişkende de bireyin kendinden memnun olma durumu söz konusudur. Hatta bu iki psikolojik yapının ayrı ya da benzer yapılar olduğu tartışılmakta ve anlamlı olarak ilişkili olduğu ifade edilmektedir (Lyubomirsky, Tkach ve Dimatteo, 2006). Bu nedenle benlik saygısı yüksek olan bireylerin de yüksek düzeyde yaşam doyumuna sahip olmaları beklenmektedir. 
Yapılan araştırmada da problem çözme ile benlik saygısı arasındaki ilişkiyi inceleyen araştırmaların etki büyüklükleri 0.19 ile 0.51 arasında değişmektedir ve genel etki büyüklüğü 0.32 olarak elde edilmiştir. Araştırmalarda, problem çözmede kendine güveni olanların, problemden kaçmak yerine yüzleşmeyi seçenlerin daha az sorun bildirdikleri, benlik algılarının daha olumlu olduğu, fiziksel ve psikolojik sağlıklarının daha iyi olduğu, depresyon düzeylerinin daha düşük olduğu belirtilmektedir (Atabay, 2004). Elde edilen bu sonuç literatür ile uyum göstermektedir ve problem çözme becerisi ile benlik saygısı arasında orta düzey etki büyüklügünü göstermektedir.

Araştırmada benlik saygısı ile etki büyüklüğü incelenen son ilişkisel faktör empati değişkenidir. Meta-analiz kapsamına alınan çalışmaların etki büyüklüğü 0.31 olarak elde edilmiştir. Araştırmaya dâhil edilen tüm çalışmalarda pozitif etki büyüklüğü görülmüştür. Benlik saygısı küçük yaştan itibaren bireyin sosyal etkileşimi sonucu oluşmaktadır. Kişinin çevresindeki bireyleri ona karşı değerli hissettiren ve empatik yaklaşımları, olumlu ve yüksek benlik saygısının gelişmesinde önemli rol oynamaktadır (Rosenberg ve Turner, 1990). Bireylerin benlik saygısı yardımıyla sosyal alanda empatik olma eğilimi sosyal veya yakın ilişkilere olumlu yansır ve bu da ruh sağlığına katkıda bulunur. Sonuç olarak benlik saygısının ruh sağlığı üzerindeki etkisinin bireyin empatik eğilimlerine aracılık edebileceği varsayılmaktadır (Şimşek ve Bozanoğlu, 2011).

\section{Sonuç}

Yapılan araştırmada benlik saygısı ile ilişkili faktörlere ait korelasyon değerlerinin etki büyüklüklerinin hesaplanması amaçlanmıştır. Bu amaç doğrultusunda elde edilen korelasyon değerleri meta-analiz yöntemi ile birleştirilerek genel etki büyüklüğü elde edilmiştir. Elde edilen etki büyüklükleri Şekil 1'de gösterilmiştir. Şekil 1'de görüldüğü üzere benlik saygısı ile en büyük etki büyüklüğüne sahip risk faktörleri sırasıyla yalnızlık, sosyal görünüş kaygısı, çocukluk çağı travması, depresyon, stres, anksiyete ve güvenli olmayan bağlanmadır. Benlik saygısı ile en büyük etki büyüklüğüne sahip koruyucu faktörler ise sırasıyla psikolojik sağlamlık, öz yeterlik, yaşam doyumu, problem çözme becerisi, algılanan sosyal destek, empati ve güvenli bağlanmadır.

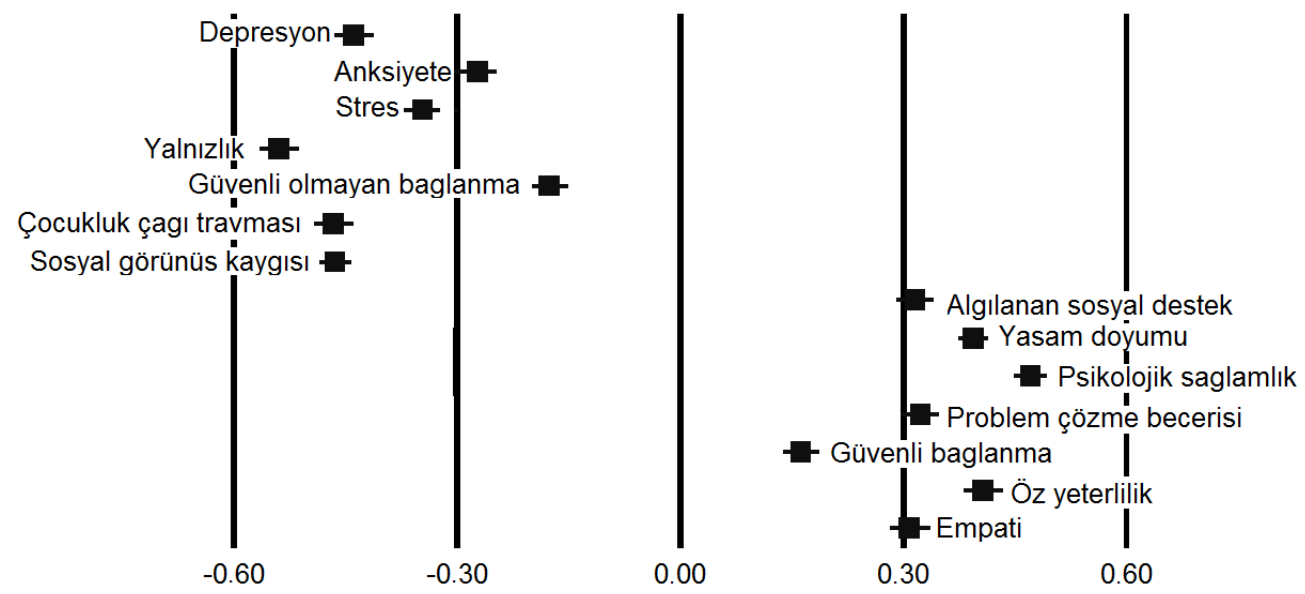

Şekil 1. Benlik Saygısı ve İlişkisel Faktörlerin Etki Büyüklüğü Grafiği 
Araştırmada, benlik saygısı ile ilişkisi incelenen risk faktörleri ile benlik saygısı üzerinde etki büyüklüğüne ilişkin genel bir sonuç elde etmek amacı ile 2010-2019 yılları arasında yapılan ve Türkiye örnekleminde gerçekleştirilen çalışmalar incelenmiştir. Bu bağlamda yapılan araştırmaya sadece Türkiye'de gerçekleştirilen çalışmalar dâhil edilmiş ve yapılacak benzer nitelikteki uluslararası çalışmalar ile tekrarlanması araştırma sonuçlarının genellenebilirliğine ve Türkiye' de ve dünyada elde edilen sonuçların karşılaştırılmasına katkı sağlayacaktır. Yapılan araştırmada benlik saygısı ile depresyon, anksiyete, stres, yalnızlık, güvenli olmayan bağlanma, çocukluk çağı travması, sosyal görünüş kaygısı, algılanan sosyal destek, yaşam doyumu, psikolojik sağlamlık, problem çözme becerisi, güvenli bağlanma, öz-yeterlik ve empati arasındaki korelasyonlara yönelik etki büyüklükleri hesaplanmış olup araştırmanın farklı ilişkisel faktörler ile tekrar edilmesi benlik saygısı kavramının daha iyi anlaşılmasına katkı sağlayacaktır. Benlik saygısı konulu çalışmalar her yıl artarak devam etmekte ve literatüre yeni çalışmalar eklenmektedir. Benzer çalışmanın yeni çalışma bulguları eklenerek tekrarlanması elde edilen etki büyüklüklerinin zaman içinde değişimin gözlenmesine ve tartışılmasına katkı sağlayacaktır. Yapılan araştırma ile benlik saygısı hakkında genel bir sonuç elde edilmiş olup araştırma kapsamında incelenen değişkenler ile benlik saygısı arasındaki ilişkilerin etki büyüklükleri tespit edilmiştir. Benlik saygısı geliştirme programlarında araştırma bulgularından yararlanılabilir, benlik saygısı ile yüksek düzeyde pozitif/negatif ilişkiye sahip faktörler gerçekleştirilecek psiko-sosyal programlarda öncelikli olarak değerlendirilebilir.

\section{Kaynaklar}

Arslan, H., Mergen, H., Erdoğmuş Mergen, B., Arslan, E. ve Ayyıldız, Ü. (2016). Eğitim fakültesi öğrencilerinin depresyon, anksiyete ve benlik saygısı puanlarının farklı değişkenler açısından değerlendirilmesi. Medical Sciences, 11(1), 1-13.

Bandura, A. (1997). Self-efficacy: The exercise of control. New York: W. H. Freeman.

Weiner, I. B. ve Craighead, W. E. (Ed.). The Corsini Encyclopedia of Psychology. New York: Wiley.

Bartholomew, K. ve Horowitz, L. M. (1991). Attachment styles among young adults: a test of a fourcategory model. Journal of Personality and Social Psychology, 61(2), 226-244.

Baumeister, R. F., Campbell, J. D., Krueger, J. I. ve Vohs, K. D. (2003). Does self-esteem cause better performance, interpersonal success, happiness or healthier lifestyles? Psychological Science in the Public Interest, 4(1), 1-44.

Bowlby, J. (1973). Attachment and loss: Seperation, anxiety and anger. New York: Basic Books

Burger, J., M. (2006). Kişilik (İ. Deniz, Erguvan Sarığlu, Çev). İstanbul: Kaknüs Yayıncılık. 
Burma, R. (2012). Cinsel saldırı suçu işlemiş hükümlülerde, çocukluk döneminde örseleyici yaşantılara maruz kalma düzeyi ile benlik saygısı, öfke ifade tarzı arasındaki ilişkinin incelenmesi. Yayımlanmamış yüksek lisans tezi, M. Ü. Sosyal Bilimler Enstitüsü, İstanbul.

Byrne, J. S. ve O'brien, E. J. (2014). Interpersonel views of narcissism and authentic high self-esteem: It is not all about you. Psychological Reports: Relationships and Communications, 115(1), 243-260.

Canlı, Y. (2017). Anne-babası boşanmış 12-15 yaşındaki çocuklar ile aynı yaş grubundaki anne-babası boşanmamış çocukların benlik saygısı ve depresyon düzeylerinin karşılaştııılması. Yayımlanmamış yüksek lisans tezi, İ. A. Ü. Sosyal Bilimler Enstitüsü, İstanbul.

Card, N. A. (2015). Applied meta-analysis for social science research. New York: Guilford Publications.

Cervone, D. ve Pervin, L. A. (2016). Kişilik psikolojisi: Kuram ve araştırma. Ankara: Nobel Akademik Yayıncilik.

Chao, R. C., Vidacovich, C. ve Green, K. E. (2017). Analysis of the Rosenberg self-esteem scale with African Americans. Psychological Assessment, 29(3), 329-342.

Cochran, W. G. (1954). The combination of estimates from different experiments. Biometrics, 10, 101129.

Cohen, L., Manion, L. ve Morrison, K. (2007). Research methods in education. London: Routledge-Falmer.

Copel, L.C. (1988). Loneliness: A conceptual model. Journal of Psychosocial Nursing and Mental Health Nursing, 26(1),14-19.

Cumming, G. (2012). Understanding the new statistics. New York: Routledge, Taylor and Francis Group.

Çakar, F. S. ve Karataş, Z. (2012). Ergenlerin benlik saygısı, algıladıkları sosyal destek ve umutsuzluk düzeyleri: Bir yapısal eşitlik modeli çalışması. Educational Sciences: Theory ve Practice, 12(4), 2397-2412.

Çoban, Ü. (2019). Üniversite öğrencilerinin spora yönelik tutumlarının benlik saygısı, yaşam kalitesi, öz yeterlilik ve akademik başar düzeylerine etkisinin incelenmesi (Doğu Marmara Bölgesi üniversiteleri örneği). Yayımlanmamış doktora tezi, K.Ü. Sağlık Bilimleri Enstitüsü, Kocaeli.

Diener, E. (1984). Subjective well being. Psychological Bulletin, 95(3), 542-575.

Dinçer, S. (2014). Ĕğitim bilimlerinde uygulamalı meta-analiz. Ankara: Pegem Akademi.

Ernst, J. M. ve Cacioppo, J. T. (1999). Lonely hearts: Psychological perspectives on loneliness. Applied and Preventive Psychology, 8, 1-22.

Fennell, M. J. (1997). Low self-esteem: A cognitive perspective. Behavioural and Cognitive Psychotherapy, 25(1), 1-26. 
Gardner, D. G. ve Pierce, J. L. (1998). Self-esteem and self-efficacy within the organizational context. Group and Organization Management, 23(1), 48-70.

Gerring, R. J. ve Zimbardo, P.G. (2012). Psikoloji ve yaşam (G. Sert, Çev.). Ankara: Nobel.

Gizir, C. A. (2007). Psikolojik sağlamlık, risk faktörleri ve koruyucu faktörler üzerinde bir derleme çalışması. Türk Psikolojik Danışma ve Rehberlik Dergisi, 3(28), 113-128.

Goldsmith, D. J. (2008). Communicating social support. USA: Cambridge University Pres.

Gorrese, A. ve Ruggieri, R. (2013). Peer attachment and self-esteem: A meta-analytic review. Personality and Individual Differences, 55(5), 559-568.

Hao, J. ve Wilkinson, R. B. (2014). Adult Attachment and Self-Esteem: A Meta-Analysis. In Conference Paper Presented at the International Association for Relationship Research Biennial Conference, At Melbourne, Australia.

Hart, T. A., Flora, D. B., Palyo, S. A., Fresco, D. M., Holle, C. ve Heimberg, R. G. (2008). Development and examination of the social appearance anxiety scale. Assessment, 15(1), 48-59.

Hazan, C. ve Shaver, P. (1987). Romantic love conceptualized as an attachment process. Journal of Personality and Social Psychology, 52(3), 511-524.

Higgins, J. P. T. ve Thompson, S. G. (2002). Quantifying heterogeneity in a meta analysis. Statistics in Medicine, 21, 1539-1558.

Işın, S. A. (2015). Akademik başarı düzeyi yüksek olan ergenlerin benlik saygısı ve anksiyete düzeyleri arasındaki ilişkinin incelenmesi. Yayımlanmamış yüksek lisans tezi, Ü. Ü. Sosyal Bilimler Enstitüsü, İstanbul.

Jackson, J. ve Cochran, S. D. (1991). Loneliness and psychological distress. Journal of Psychology, 125(3), 257-262.

Judge, T. A. ve Bono, J. E. (2001). Relationship of core self-evaluations traits-self-esteem, generalized self-efficacy, locus of control, and emotional stability-with job satisfaction and job performance: A meta-analysis. Journal of Applied Psychology, 86(1), 80-92.

Jumper, S. A. (1995). A meta-analysis of the relationship of child sexual abuse to adult psychological adjustment. Child Abuse ve Neglect, 19(6), 715-728.

Kan, M. (2018). Üniversite öğrencilerinde yetişkin bă̆lanma biçimleri, kişilik özellikleri ve benlik saygısı arasındaki ilişkiler. Yayımlanmamış yüksek lisans tezi, Ü. Ü. Sosyal Bilimler Enstitüsü, İstanbul.

Karaca, N. H., Akyol, T., Karaca, L. ve Can Yaşar, M. (2016). Okul öncesi öğretmen adaylarının problem çözme becerileri ve benlik saygılarının bazı değişkenlere göre incelenmesi. Afyon Kocatepe Üniversitesi Sosyal Bilimler Dergisi, 18(1), 199-220. 
Karadağ, E. ve Sölpük, N. (2018). Türkiye'de Yapılan Çalışmalarda Depresyon ve Kaygı İlişkisi: Bir Meta-Analiz Çalışması. Düşünen Adam, 31(2), 163-176.

Karaırmak, Ö. (2006). Psikolojik sağlamlık, risk faktörleri ve koruyucu faktörler. Türk Psikolojik Damışma ve Rehberlik Dergisi, 3(26), 129-142.

Karaırmak, Ö. ve Siviş-Çetinkaya, R. (2011). Benlik saygısının ve denetim odağının psikolojik sağlamlık üzerine etkisi: duyguların aracı rolü. Türk Psikolojik Danışma ve Rehberlik Dergisi, $4(35), 30-43$.

Karasar, N. (2005). Bilimsel araştırma yöntemleri. Ankara: Nobel Yayın Dağıtım.

Kayal, M. (2018). Illköğretim düzeyinde öğrenim gören roman öğrencilerde benlik saygısı, algılanan sosyal destek ve sosyal beceriler. Yayımlanmamış yüksek lisans tezi, N. Ü. Sosyal Bilimler Enstitüsü, İstanbul.

Kılınç, S. ve Torun, F. (2011). Türkiye'de klinikte kullanılan depresyon değerlendirme ölçekleri. Dirim Tip Gazetesi, 86(1), 39-47.

Korkut-Owen, F. (2015). Okul temelli önleyici rehberlik ve psikolojik danışma. Ankara: Anı.

Kulaksızoğlu, A. (2011). Ergenlik psikolojisi. İstanbul: Remzi Kitabevi.

Lyubomirsky, S., Tkach, C. ve DiMatteo, M. R. (2006). What are the differences between happiness and selfesteem. Social Indicators Research, 78(3), 363-404.

Mattanah, J. F., Lopez, F. G., \& Govern, J. M. (2011). The contributions of parental attachment bonds to college student development and adjustment: a meta-analytic review. Journal of Counseling Psychology, 58(4), 1-32.

Miller, C. T. ve Downey, K. T. (1999). A meta-analysis of heavyweight and self-esteem. Personality and Social Psychology Review, 3(1), 68-84.

Morgan, C. T. (2010). Psikolojiye giriş. Konya: Eğitim Yayınevi.

Özcan, H., Subaşı, H., Budak, B., Çelik, M., Gürel, Ş. C. ve Yıldız, M. (2013). Ergenlik ve genç yetişkinlik dönemindeki kadınlarda benlik saygısı, sosyal görünüş kaygısı, depresyon ve anksiyete ilişkisi. Journal of Mood Disorders, 3(3), 107-113.

Özgözgü, S. ve Altunay, E. (2016). Yöneticilerin liderlik davranışlarının öğretmenlere yansıyan sonuçları: Bir meta-analiz çalışması. Manisa Celal Bayar Üniversitesi Sosyal Bilimler Dergisi, 14(4), 259-294

Pavot, W. ve Diener, E. (1993). Review of the satisfaction with life scale. Psychological Assessment, 5(2), 164-172. 
Petitti, D. B. (2000). Meta-analysis, decision analysis and cost effectiveness analysis: Methods for quantitative synthesis in medicine. NY: Oxford University Press.

Rhodewalt, F. ve Peterson, B. (2008). The self and social behavior: The fragile self and interpersonal self-regulation. Personality and social behavior içinde (ss. 49-78). New York: Psychology Press.

Richards, F. ve O'Keeffe, Z. C. (2004). Resilience and risk factors associated with experiencing childhood sexual abuse. Child Abuse Review, 13(5), 338-352.

Robinson, M. J. V., Lloyd, C. A. ve Rowe, K. J. (2008). The impact of leadership on student outcomes: An analysis of the differential effects of leadership types. Educational Administration Quarterly, 44(5), 635-674.

Rosenberg, M. (1965). Society and the adolescent self-image. Princeton, NJ: Princeton University Press.

Rosenberg, M. ve Turner, R. H. (1990). The self concept social product an social force social psychology. New Brunswick: Transaction Publisher.

Sedgwick, P. (2013). Meta-analyses: How to read a funnel plot. Bmj, 346, f1342.

Sowislo, J. F. ve Orth, U. (2013). Does low self-esteem predict depression and anxiety? A meta-analysis of longitudinal studies. Psychological, Bulletin, 139(1), 213.

Soylu, C. (2016). Orta yetişkinlikte benlik saygısı, hayatın anlamı ve psikososyal uyum arasındaki ilişkiler: meme kanseri hasta örneklemi. Yayımlanmamış yüksek lisans tezi, H. Ü. Sosyal Bilimler Enstitüsü, Ankara.

Şimşek, Ö. F. ve Bozanoğlu, İ. (2011). From self-esteem to mental health: Empathy as mediator. Eğitim Araştırmalari-Eurasian Journal of Educational Research, 42, 225-242.

Traş, Z., Arslan, C. ve Mentiş Taş, A. (2011). Öğretmen adaylarında mizah tarzları, problem çözme ve benlik saygısının incelenmesi. Uluslararası İnsan Bilimleri Dergisi, 8(2), 716-732.

Türk Dil Kurumu (TDK, 219). Benlik. https://sozluk.gov.tr/?q=benlikvearanan= adresinden alınmıştır.

Videbeck SL (2001). Psychiatric mental health nursing. Lippincott: Williams ve Wilkins.

Whirter, J. M. ve Voltan-Acar, N. (1985). Çocukla iletişim. Ankara: Nüve.

Woolfolk, A. (2004). Educational psychology (9th Ed.). New Jersey: Pearson Internationa Edition.

Yersel, Z. (2019). Çocuk ve ergenlerde anne-baba tutumu ve bağlanma durumunun algıladıkları benlik saygısı ve çocukluk çă̆g narsisizmi ile ilişkisi. Yayımlanmamış yüksek lisans tezi, B. Ü. Sosyal Bilimler Enstitüsü, İstanbul.

Yılmaz Irmak, T. (2008). Çocuk istismarı ve ihmalinin yaygınlığı ve dayanıklılıkla ilişkili faktörler. Yayımlanmamış doktora tezi, E. Ü. Sosyal Bilimler Enstitüsü, İzmir.

Yörükoğlu, A. (1985). Gençlik çă̆ı (7. Bas.). İstanbul: Özgür Yayınları. 
Yörükoğlu, A. (1990). Çocuk ruh să̆ğı̆̆g: Çocuk yetiştirme sanatı ve kişilik gelişimi. İstanbul: Özgür Yayınları.

\section{Extended Summary}

\section{Self-Esteem and Relational Factors: A Meta-Analysis Study}

Thinking, which is one of the basic abilities of human beings, has led people to think and make a judgment both on the environment and on themselves starting from nature. The first concept that we encounter in this journey of the person who thinks about oneself and tries to understand oneself is the self-concept. Self is a concept that includes personality traits, values, beliefs, desires, and evaluations about oneself. Self-esteem can be expressed as evaluations made by the person on these qualifications, while the concept of self means self-made qualifications. Self-esteem is a structure that includes feelings, thoughts, and beliefs about one's self (Rosenberg, 1986). There are a number of factors that directly or indirectly affect the individual's low and high self-esteem. These factors may vary from person to person (Burger, 2006).

When we look at the factors affecting self-esteem in the literature, we can say that there are many factors. Some of these factors are associated with high self-esteem, while others are associated with low self-esteem. Factors related to high self-esteem that are considered within the scope of the research are protective factors; factors associated with low self-esteem are grouped under the name of risk factors. Risk factors generally include psycho-social factors that can lead to problems occurring or increasing (Korkut Owen, 2015). Protective factors, on the other hand, can be expressed as factors that make it easier for the person to give constructive responses in the face of negative experiences in contrast to the risk factors (Karairmak, 2006).

The risk factors considered within the scope of the research aredepression, anxiety, stress, loneliness, insecure attachment types, childhood trauma, and social appearance anxiety. Protective factors are perceived social support, life satisfaction, psychological resilience, problem-solving ability, secure attachment, self-efficacy, and empathy. In line with these explanations, the problem statement of the research is "What is the effect size and level of relationship between self-esteem and risk factors (depression, anxiety, stress, loneliness, insecure attachment types, childhood trauma, and social appearance anxiety); and protective factors(perceived social support, life satisfaction, psychological resilience, problem-solving ability, secure attachment, self-efficacy, and empathy)?"

In the study, it is aimed to obtain a general result regarding the effect size of the protective factors and the risk factors on self-esteem. For this purpose, a meta-analysis of the correlational studies between self-esteem and relational factors determined in the study was conducted. Since the strength 
of the factors associated with self-esteem may change over time, and the studies on self-esteem contain a large part of them, the studies of the last ten years are included in the study.

The main data source of the research is self-esteem studies in Turkey and the articles published in peer-reviewed scientific journals that deal with the relational factors studied in the research and the graduate theses written in Turkey. In the meta-analysis study, 1151 studies were examined. 153 different studies that met the research criteria were examined within the scope of the study and 237 effect sizes were calculated from these studies. There were $106(69 \%)$ of dissertations and $47(31 \%)$ articles.

The studies with self-esteem and relational factors reviewed within the scope of the research have been coded clearly and in detail by developing a coding method to convert them into categorical variables before being included in the meta-analysis. The data have been encoded by two independent coders in order to ensure reliability. The Cohen kappa coefficient was calculated and found to be $\kappa=0.90$ (perfect harmony between 0.80 and 1.00 ).

The validity of studies examined in a meta-analysis study determines its validity (Petitti, 2000). For this reason, the validity findings of all the studies included in the meta-analysis were examined, and it was observed that the studies were valid. In addition, meta-analysis studies should cover all studies examining the relevant subject (Robinson, Lloyd, and Rowe, 2008). In this context, all of the researches regarding the relational factors identified in the study were reached.

The analysis was done using Comprehensive Meta-Analysis software. The study used a random effects model in accordance with the field of Social Sciences (Cumming, 2012). Orwin's FailSafe N, Begg and Mazummar rank correlation, Egger's regression intercept analyses were performed to determine publication bias. The control of heterogeneity in research was carried out by Cochran's (1954) Q statistic and I2 statistic.

Orwin's Fail-Safe N, Begg and Mazummar rank correlation, Egger's regression intercept analyses were performed to determine broadcast bias. When the findings were examined, it was found that not all relational factors included in the study showed publication bias. In the heterogeneity test, $\mathrm{I}^{2}$ and $\mathrm{Q}$ values were tested. When the $\mathrm{Q}$ value and $\mathrm{I}^{2}$ results of the studies were examined, it was observed that all the studies were heterogeneous apart from secure attachment.

The study calculated the effect size of the relationship between fourteen factors and selfesteem. According to the findings, a large negative effect size was obtained between loneliness $(\mathrm{r}=-0.54$, $\mathrm{p}<0.05)$ and self-esteem. A negatif moderate effect size was obtained between betweem childhood trauma $(\mathrm{r}=-0.47, \mathrm{p}<0.05)$, social appearance anxiety $(\mathrm{r}=-0.46, \mathrm{p}<0.05)$, depression $(\mathrm{r}=-0.44, \mathrm{p}<0.05)$, stress $(\mathrm{r}=-0.35, \mathrm{p}<0.05)$, and self-esteem A negative effect size was obtained between anxiety $(\mathrm{r}=-0.27, \mathrm{p}<0.05)$, insecure attachment $(\mathrm{R}=-0.18, \mathrm{p}<0.05)$, and self-esteem. 
When examining the effect size of the relationship between protective factors, psychological stability $(r=0.47, \mathrm{p}<0.05)$, self efficacy $(\mathrm{r}=0.41, \mathrm{p}<0.05)$, life satisfaction $(\mathrm{r}=0.39, \mathrm{p}<0.05)$, perceived social support $(\mathrm{r}=0.32, \mathrm{p}<0.05)$, problem-solving skills $(\mathrm{r}=0.32, \mathrm{p}<0.05)$, empathy $(\mathrm{r}=0.31, \mathrm{p}<0.05)$, and selfesteem, a positive moderate effect size was obtained. A positive-directional small effect size was obtained between secure attachment $(\mathrm{r}=0.16, \mathrm{p}<0.05)$ and self-esteem.

Studies on self-esteem date back to the 1980s, but studies have been increasing every year from past to present, and studies carried out in the last decade constitute a very large proportion of the total studies. Due to the fact that the research is carried out in the light of the current data and that it constitutes the majority of the total studies, the studies of the last ten years have been included. Only studies performed in Turkey are included in the study. In addition, dissertations and articles were preferrred because they were examined by juries and referees, respectively.

The narrow confidence intervals of the findings obtained from the meta-analysis indicate that the results of the study are reliable. The $Q$ values of the Meta-analysis were higher than the kay square values. These values mean that the studies show a heterogeneous distribution. The resulting effect magnitudes provide reliable findings of the direction and strength of the relationships studied in the research. In this respect, it can be considered as an important finding. The effect magnitudes of the risk factors associated with self-esteem are loneliness, childhood trauma, social appearance anxiety, depression, stress, anxiety, insecure attachment form in order. The largest effect sizes between selfesteem and protective factors are psychological robustness, self-efficacy, life satisfaction, perceived social support, problem-solving ability, empathy, and safe attachment, respectively

Although a negative relationship is expected to occur between loneliness and self-esteem, it is quite meaningful that the effect size of the relationship between them is quite large. Loneliness is a strong emotion, and socio-demographic changes exacerbate this situation (Ernst and Cacioppo, 1999). With modernization in our country, a cultural transformation is taking place, and individuality is becoming more supported. Childhood traumas express some experiences of neglect and abuse experienced in the early period and have negative effects on the development process (Kulaksizoğlu, 2011; Richards and O'keeffe, 2004). Socio-economic inadequacies, fragmented families, and domestic unhappiness provide the basis for such neglect and abuse (Kara, Biçer, and Gökalp, 2004). As a result, problems such as insecure attachment, low self-esteem, school failure, behavior problems, turning to crime, and depression may occur (Yilmaz Irmak, 2016).

Self-esteem is a state of appreciation or satisfaction that occurs as a result of one's selfassessment. The level of this liking condition leads to high or low self-esteem. There are many factors that may be associated with high or low self-esteem. Research shows that individuals with high self- 
esteem receive more social support and are appreciated by other individuals (Kayal, 201; Soylu, 2016; Taşören, 2013).

Yalcin (2014) examined the relationship between social support and various variables through meta-analysis. In his research, he found that social support was positively associated with well-being and negatively associated with depression and loneliness. Yalcin (2014) also obtained an effect magnitude of 0.24 between social support and self-esteem in his research. The research findings confirm the magnitude of the effect we achieved in our study. 